\title{
Photovoltaic panels identification in aerial images
}

\author{
Raphael S. Medeiros, Felipe Ximenes, Aurelio G. Melo, Jose Antonio F. de C. R. Rodrigues, João T. Dias, \\ Luciana Faletti, e Milena F. Pinto
}

\begin{abstract}
The solar power generation is increasing rapidly around the world. These systems are often installed on roofstops and other structures that are difficult to access. Despite this difficulty, regular inspection of the system is a requirement to ensure efficiency. As a result, a challenge arise to develop efficient and low-cost inspection methods to monitor structural failures, dirt and other characteristics of the system. Thus, in this work an Unmanned Aerial Vehicle was used to carry out the inspection, obtaining critical images that are necessary to the solar panels maintenance and a machine learning algorithm was applied to identify them.
\end{abstract}

Keywords-UAV, Image Processing, Photovoltaic Cells, Machine Learning.

Resumo-A geração de energia solar está aumentando rapidamente em todo o mundo. Esses sistemas são frequentemente instalados em topos de telhado e outras estruturas de difícil acesso. Apesar dessa dificuldade, a inspeção regular do sistema é um requisito para garantir a eficiência. Como resultado, surge o desafio de desenvolver métodos de inspeção eficientes e de baixo custo para monitorar falhas estruturais, sujeira e outras características do sistema. Assim, neste trabalho foi utilizado um Veículo Aéreo Não Tripulado para realizar a inspeção, obtendo-se imagens críticas necessárias à manutenção dos painéis solares e aplicado um algoritmo de aprendizado de máquina para identifica-los.

Palavras-Chave-VANT, Processamento de Imagem, Paineis Solares, Aprendizagem de Maquina.

\section{INTRODUCTION}

The sustainable use of renewable energies presents fundamental challenges, such as energy management, playing a crucial role in energy efficiency and savings for future generations. The operation and maintenance of energy systems is a precious activity to prevent losses. Accurate monitoring can detect failures, dirty and equipment degradation in advance $[1,2]$.

Note that solar energy has many advantages, such as decentralized installation, a long life span, few or no moving parts, and is noise-free. However, disadvantages include the fact that it is limited due to intermittent energy, low energy density, high startup costs, and dependence on weather conditions. Therefore, an in-depth investigation into the effects of

Raphael S. Medeiros, Departamento de Engenharia Eletrônica, CEFET/RJ, Rio de Janeiro-RJ, e-mail: medeiros.ph@gmail.com; Felipe Ximenez, Programa de Pós-Graduação em Engenharia Elétrica, CEFET/RJ, Rio de Janeiro-RJ, ximenesfel@gmail.com; Aurelio G. Melo, Programa de Pós-Graduação em Engenharia Elétrica, UFJF, Juiz de Fora-MG, email: aurelio.melo@engenharia.ufjf.br; Jose Antonio Fontes de Carvalho Ribeiro Rodrigues, Coordenadoria de Eletrônica, CEFET/RJ, Rio de JaneiroRJ, e-mail: joseantoniofontes@gmail.com; João T. Dias, Programa de PósGraduação em Engenharia Elétrica, CEFET/RJ, Rio de Janeiro-RJ, e-mail: joaotdias@yahoo.com.br; Luciana A. Faletti, Programa de Pós-Graduação em Engenharia Elétrica, CEFET/RJ, Rio de Janeiro-RJ, e-mail: lucianafaletti@gmail.com; Milena F. Pinto, Programa de Pós-Graduação em Engenharia Elétrica, CEFET/RJ, Rio de Janeiro-RJ, e-mail: milena.pinto@ cefet-rj.br. degradation on photovoltaic modules is essential to guarantee the performance and reliability of systems [3, 4].

Photovoltaic (PV) panels' visual inspection is an initial activity of the maintenance cycle, and its effectiveness is essential in determining the system's reliability and maintenance costs. The increased installation and distribution of photovoltaic systems over a large area has imposed urgent challenges for efficient and low-cost methods for inspection to monitor functionality and performance $[5,6]$. This application has recently been explored using Unmanned Aerial Vehicles (UAVs) [7, 8], where the characterization of defective elements can be done with thermal and aerial visual imaging in order to speed up the scanning of the system and allow a diagnosis prior.

In the last years, the application of UAV platforms has attracted huge interest in many applications [9, 10, 11]. The reason relies on the fact that they are low-cost systems, flexible, and easy to control. The UAVs use in PV monitoring allows obtaining reliable information for diagnosis. This method offers a lower cost than employing specialized personnel in challenging areas. Other advantages are automated detection, wide-area coverage, precision in defect detection, among others [2].

UAVs can bring more efficiency to missions by replacing the human operator [12]. Also, the integration of complex algorithms and methods that work onboard the aircraft system has developed many highly specialized solutions for specific applications [13].

Thus, it is possible to develop a specialized system to be shipped on a semi-autonomous UAV to carry out the monitoring and inspection of PV panels. However, it is essential to note that a crucial step in the inspection process is the correct choice of efficient sensing, instrumentation, and monitoring systems. Therefore, it is necessary to use simulation software as close as possible to the real environment to test the project to be developed safely.

\section{A. Main Contributions}

Therefore, this article aims to propose an identification system that can be used onboard a UAV to enable a fast and economical monitoring method for inspection PV panels in the aerial image. For the system test, the GAZEBO [14] software was used, which allows an accurate simulation of the dynamics of the robotic system and shows how the UAV will behave in a real operating environment. The main contributions of this work can be summarized as follows:

- Low-cost method for identification of PV system for preliminary inspections;

- Proposition of simulations for validating inspection techniques for PV modules. 
- Performance validation in real solar panel images.

\section{B. Organization}

This work is divided as follows: Section II details the methodology developed in this work as well as the functionalities and mathematical foundations. Section III presents the results and the relevant discussions. The conclusions and ideas for future work can be seen in Section IV.

\section{MATERIAls AND Methods}

The proposed system's main idea is represented in Figure 1, where a UAV performs a mission flying over a PV field to collect images from solar panels.

For this experimental setup, was used a robot in the Gazebo simulation environment. The UAV 'Hector_Quadrotor', proposed by Meyer et al. [15] was used in the experiments. The training was performed in a computer supplied with an integrated GPU Intel HD graphics 620, 12 GB of RAM, Intel(R) Core(TM) i5-7200 2.50 GHz processor, Ubuntu 18.04 (Bionic Beaver) as the operating system. It was used the Robot Operating System (ROS), Melodic version distribution, for developing the controller, and camera nodes packages.

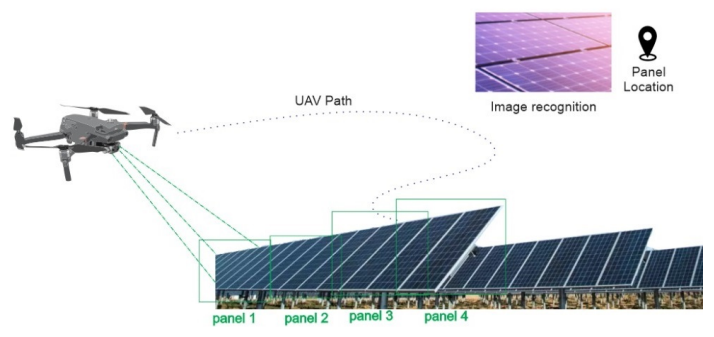

Fig. 1. Proposed inspection architecture.

Figure 2 presents the proposed inspection process diagram. Initially, both hardware and ROS are initialized. Then, the navigation and vision sensors are verified along with communication and storage systems. Case the sensors and all involved systems are in a good state, the path planning and the computer vision algorithms are initialized. The UAV goes to an initial altitude and to a home position to start the mission. This altitude enables the solar panel to be in the field of view (FOV) of the UAV. If any change is identified, the aircraft gets closer to the panel and hovers for 2 seconds to acquire enough photos. Then, it backs to the starting mission. Every time that the UAV moves to the next waypoint, it is verified the end of the mission.

Figure 3 presents the machine learning (ML) model that will be used in this work. The images from the database are annotated in two classes, which are solar panel and nonsolar panel objects. Then, the machine learning stats process, where the images are divided into validation, test, and training groups.

\section{A. Feature Extraction}

The Histogram of Oriented Gradients(HOG) is a popular feature descriptor that can work together with supervised

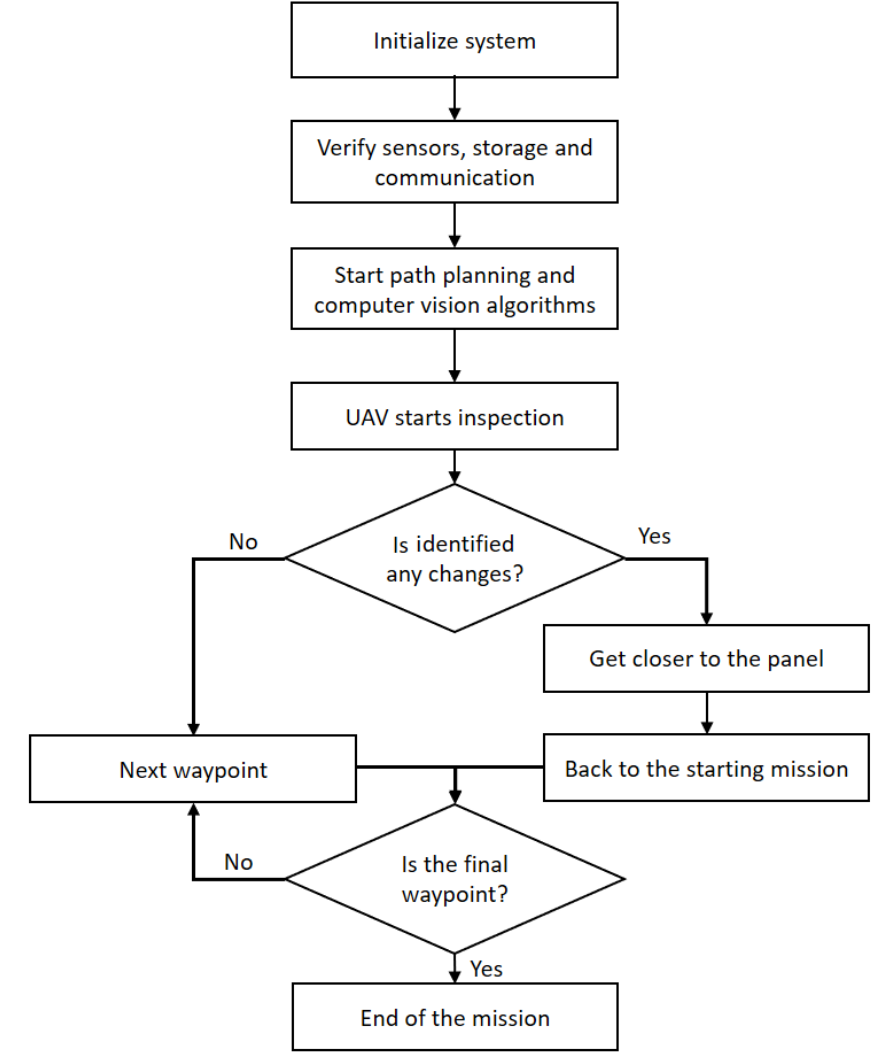

Fig. 2. Diagram of the proposed inspection process.

learning techniques, such as Support Vector Machine (SVM), to detect people and objects. The function $\mathrm{HOG}$ used in this work is a function of the scikit-image library [16]. This function receives a single color channel or grayscale image as an input and several parameters. These parameters include orientations, pixels per cell, and cells per block.

HOG is similar to edge-oriented histograms [17], descriptors SIFT [18] and shape contexts [19]. One of the differences is in the fact that the descriptors are calculated in a dense grid of densely spaced cells with overlap between them.

The feature descriptor is capable of converting images with dimensions width $\times$ height $\times 3$ (number of RGB channels) into a vector of size $n$. Dalal and Triggs [20] used an image of dimensions $64 \times 126 \times 3$, which resulted in a vector of 3780 elements. Different sizes can be used, but for didactic purposes, the same dimensions mentioned will be used. In this method, the distribution of the direction of the gradients is used as a characteristic for the classifier, which will return the presence or absence of a person in the image. The gradients in relation to the $x$ and $y$ axes of the image are very useful since their intensity is greater around the edges, where there is a lot of information to be obtained due to the sudden changes in the pixel intensities.

Initially, it is necessary to do a pre-processing process. Thus, a fraction of the $64 \times 128$-pixel image will be used. The size may vary, but the ratio between the sides should always remain at 1: 2 , and then the image will be scaled to $64 \times 128$ pixels. Then, to calculate a HOG descriptor, it is necessary first to calculate the horizontal and vertical gradients, that 


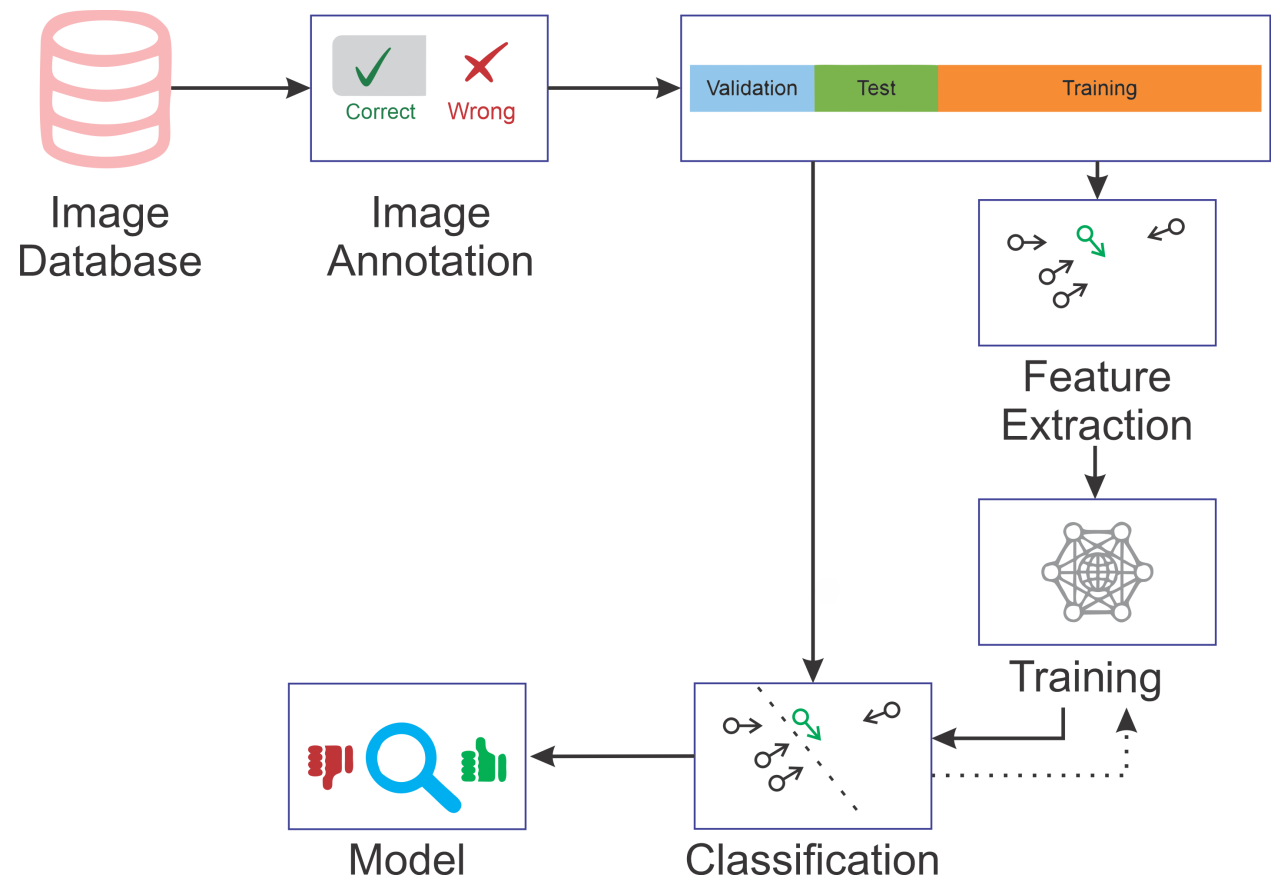

Fig. 3. SVM Model.

is, the gradients along the $x$ and $y$ axes, since you want to calculate the gradient histogram. After calculating the total magnitude of the gradients, we have the Equations 1 and 2, which respectively represent the modulus and angle of the gradients. Note that the intensity of the gradients is greater at the points where there is more significant color variation.

$$
\begin{aligned}
& g=\sqrt{g_{x}^{2}+g_{y}^{2}}, \\
& \theta=\arctan \left(\frac{g_{y}}{g_{x}}\right)
\end{aligned}
$$

Then, the image must be divided into cells of dimensions 8 $\times 8$ to allow the characteristic descriptor to provide a compact description of the image. The histogram in the HOG method is a vector with nine positions, with each one indicating a direction and its respective value representing the intensity of the gradient. Then, the process of extracting characteristics goes through a normalization of the histogram values to make them more insensitive to lighting variations.

\section{B. Image Correction}

After extracting the images, it is necessary to filter the best angles to compose the material (dataset) for training, testing, and validation. Besides, it is necessary to convert this selection to the following $64 \times 64$ dimensions. Note that this is the mandatory resolution for the HOG to apply the solar plate detection method. This first image is divided into 9 square parts as shown in Figure 4.

\section{Support Vector Machine}

SVM is a type of ML method that makes usage of statistical learning to data classification problems. Its main advantage is

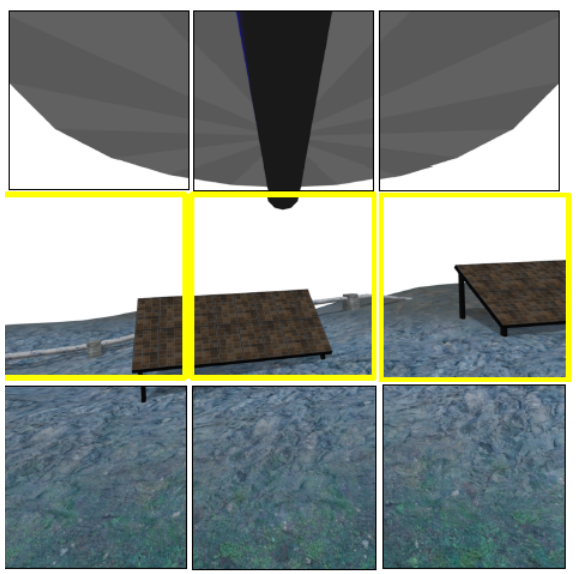

Fig. 4. Image division for decreasing resolution.

performing classification in complex problems with minimal input training data and high computational efficiency compared to deep learning.

In this implementation, the classification is performed over the feature space extracted from the images. This ensures that the panels will be recognized from any view direction and angle.

\section{RESUlts AND Discussion}

\section{A. Dataset for simulated results}

In order to build the solar panel dataset, a simulated world [21] was used in the software Gazebo, as presented in Figure 5.

A 2-minute flight over the solar panels was sufficient to generate an average of 800 images from the extraction of images from the simulated world, where 425 are panel images, 


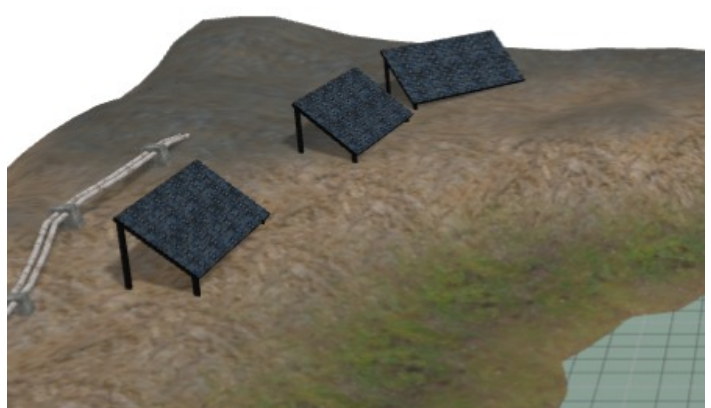

Fig. 5. Virtual world used in Gazebo.

and 375 are non-panel images. The acquired images are delivered to us in the following $1600 \times 1200$ resolution.

\section{B. Image classification}

In this stage, the author used the database described in the previous section to perform training and validate the proposed classification method. As described in this stage, a HOG descriptor was used, and the SVM was applied over the feature vector for classification.

A result of the example is shown in Figure 6. In Figure 6 (a), one can notice the red areas that are identified and in (b), the mask of the image.

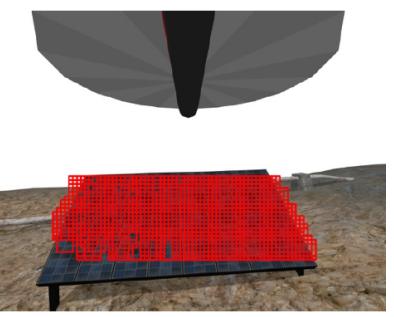

(a)

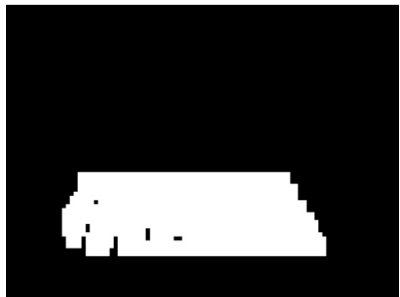

(b)
Fig. 6. Pre-processing Stage. (a) HOG features detection. (b) Threshold application.

The areas identified are combined into a single box as shown in Figure 7. This box allows the identification of the UAV's relative position when related to the panel.

Using a similar strategy, however, with images acquired from the internet, it's possible to verify the proposal's plausibility. For this, images of solar panels and other classes were used, such as images of pizzas and plants that are different classes and should not be difficult for the classifier.

No image treatment was applied to the images gathered that would flavor the classification. For each class, around 100 images were used in the database build process. The images were segmented into sets and feed into the training process.

In order to obtain a more consistent classification, a feature vector was built using three different feature describers. These are moments, HuMoments [22] that is good in finding borders of objects, Haralick [23] for extracts texture features from the
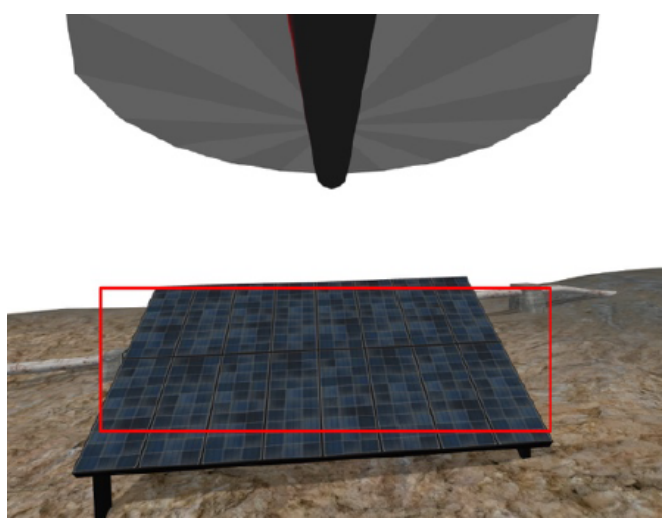

Fig. 7. SVM classification.

image and color histogram [24] that classify the object color composition.

The SVM selected uses a radial basis function (RBF) [25]. This function was selected due to its power in non-linear classification problems. The results from the training over the validation part of the method are shown in Table I. Observe that the precision was around $80 \%$ for the desired class (solar), recall of $86 \%$, and $\mathrm{F} 1$-score of $83 \%$

TABLE I

CLASSIFICATION RESULTS

\begin{tabular}{|l|l|l|l|l|}
\hline Sample & Precision & Recall & F1-score & Support \\
\hline solar & 0.80 & 0.86 & 0.83 & 14 \\
\hline roof & 0.92 & 0.79 & 0.85 & 14 \\
\hline pizza & 0.91 & 0.91 & 0.91 & 23 \\
\hline sunflower & 0.67 & 0.80 & 0.73 & 5 \\
\hline avg & 0.82 & 0.84 & 0.83 & 56 \\
\hline
\end{tabular}

We have also produced the confusion matrix for the validation set shown in Figure 8. Notice that only a few samples were miss-classified in the solar class, which shows the method's potential for deployment in real-world conditions.

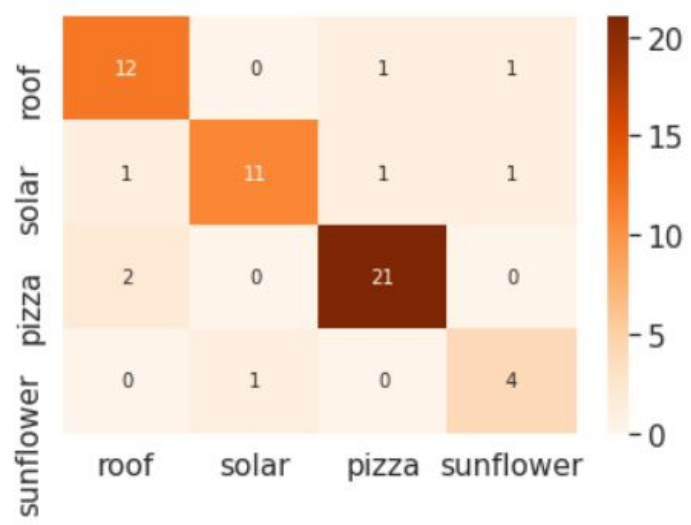

Fig. 8. Confusion matrix for the experiment.

\section{CONCLUSIONS AND FUTURE WORK}

This work proposed SVM usage to classify solar panels in aerial images. Simulated results in the Gazebo simulator show method feasibility for application in this scenario. In the 
application, this information can be used to trigger cameras and be used to adjust path planning in the future.

The tests in real panel images showed that the proposed method could be used in practice with fair accuracy, and a performance evaluation also showed that the method could be deployed in an onboard computer for online processing.

For future works, it is intended to apply path planning algorithms to assist the semi-autonomous inspections. Besides, a thermal camera will also help this first cycle of maintenance identify possible failures.

\section{ACKNOWLEDGMENT}

The authors would like to thank the following federal brazilian agencies CEFET-RJ, CAPES, CNPq and FAPERJ for the support to this work.

\section{REFERENCES}

[1] SULliVAN, G. P.; PUGH, R.; MELENDEZ, A. P. Operations and Maintenance Best Practices-A Guide to Achieving Operational Efficiency. [S.1.], 2002.

[2] GRIMACCIA, F. et al. Planning for pv plant performance monitoring by means of unmanned aerial systems (uas). International Journal of Energy and Environmental Engineering, Springer, v. 6, n. 1, p. 47-54, 2015.

[3] PETRONE, G. et al. Reliability issues in photovoltaic power processing systems. IEEE transactions on Industrial Electronics, IEEE, v. 55, n. 7, p. 2569-2580, 2008.

[4] GOLNAS, A. Pv system reliability: An operator's perspective. In: IEEE. 2012 IEEE 38th Photovoltaic Specialists Conference (PVSC) PART 2. [S.1.], 2012. p. 1-6.

[5] LI, X. et al. Visible defects detection based on uavbased inspection in large-scale photovoltaic systems. IET Renewable Power Generation, IET, v. 11, n. 10, p. 1234 1244, 2017.

[6] GRIMACCIA, F. et al. Survey on pv modules' common faults after an o\&m flight extensive campaign over different plants in italy. IEEE Journal of Photovoltaics, IEEE, v. 7, n. 3, p. 810-816, 2017.

[7] TYUTYUNDZHIEV, N. et al. Advanced pv modules inspection using multirotor uav. In: 31st European Photovoltaic Solar Energy Conference and Exhibition, Campus Sur UPM. Ctra. Valencia km. [S.1.: s.n.], 2015. v. 7.

[8] ADDABBO, P. et al. Uav system for photovoltaic plant inspection. IEEE Aerospace and Electronic Systems Magazine, IEEE, v. 33, n. 8, p. 58-67, 2018.

[9] PINTO, M. F. et al. Arcog: An aerial robotics cognitive architecture. Robotica, Cambridge University Press, p. 120, 2020.

[10] BIUNDINI, I. Z. et al. A framework for coverage path planning optimization based on point cloud for structural inspection. Sensors, Multidisciplinary Digital Publishing Institute, v. 21, n. 2, p. 570, 2021.

[11] MELO, A. G. et al. Dynamic optimization and heuristics based online coverage path planning in $3 \mathrm{~d}$ environment for uavs. Sensors, Multidisciplinary Digital Publishing Institute, v. 21, n. 4, p. 1108, 2021.
[12] PINTO, M. F. et al. Case-based reasoning approach applied to surveillance system using an autonomous unmanned aerial vehicle. In: $X X X X$. [S.1.: s.n.], 2017. p. 13241329.

[13] Yu Du; de Silva, C. W.; Dong Liu. A multi-agent hybrid cognitive architecture with self-awareness for homecare robot. In: 2014 9th International Conference on Computer Science Education. [S.1.: s.n.], 2014. p. 223-228.

[14] KOENIG, N.; HOWARD, A. Design and use paradigms for gazebo, an open-source multi-robot simulator. In: IEEE. 2004 IEEE/RSJ International Conference on Intelligent Robots and Systems (IROS)(IEEE Cat. No. 04CH37566). [S.1.], 2004. v. 3, p. 2149-2154.

[15] MEYER, J. et al. Comprehensive simulation of quadrotor uavs using ros and gazebo. In: 3rd Int. Conf. on Simulation, Modeling and Programming for Autonomous Robots (SIMPAR). [S.1.: s.n.], 2012. p. to appear.

[16] TEAM the scikit-image. Clearpath Robots. 2021. https://scikit-image.org/. Access in 23/04/2021.

[17] FREEMAN, W. T. et al. Computer vision for computer games. fg, Citeseer, v. 96, p. 100-105, 1996.

[18] LOWE, D. G. Distinctive image features from scaleinvariant keypoints. International journal of computer vision, Springer, v. 60, n. 2, p. 91-110, 2004.

[19] BELONGIE, S. J.; MALIK, J.; PUZICHA, J. Matching shapes. In: iccv. [S.1.: s.n.], 2001. v. 1, p. 454-461.

[20] DALAL, N.; TRIGGS, B. Histograms of oriented gradients for human detection. In: IEEE COMPUTER SOCIETY. international Conference on computer vision and Pattern Recognition (CVPR 05). [S.1.], 2005. v. 1, p. 886893.

[21] CLEARPATH. Clearpath Robots. 2021. https: //clearpathrobotics.com/blog/2020/ $07 /$ clearpath-simulation-environments/. Access in 23/04/2021.

[22] ZHANG, Y.-D. et al. Alcoholism detection by medical robots based on hu moment invariants and predator-prey adaptive-inertia chaotic particle swarm optimization. Computers \& Electrical Engineering, Elsevier, v. 63, p. 126$138,2017$.

[23] KORNILOV, A. S.; SAFONOV, I. V. An overview of watershed algorithm implementations in open source libraries. Journal of Imaging, Multidisciplinary Digital Publishing Institute, v. 4, n. 10, p. 123, 2018.

[24] SINGH, H. Advanced image processing using opencv. In: Practical Machine Learning and Image Processing. [S.1.]: Springer, 2019. p. 63-88.

[25] DENG, Y. et al. New methods based on back propagation (bp) and radial basis function (rbf) artificial neural networks (anns) for predicting the occurrence of haloketones in tap water. Science of The Total Environment, Elsevier, v. 772, p. $145534,2021$. 